\title{
Development of a HPLC-UV method for determination of meloxicam in human plasma and pharmaceutical dosage forms
}

\author{
Csifo Enikő, Croitoru MD, Fülöp Ibolya, Muntean Daniela-Lucia \\ University of Medicine and Pharmacy of Tirgu Mures
}

\begin{abstract}
Objectives: A simple, quick and low cost HPLC-UV method for assay of meloxicam in plasma and pharmaceutical dosage forms was developed.

Methods: Separation and assay of meloxicam, using a simple reverse phase HPLC-UV method was achieved using an Agilent Zorbax SB C18 column, with methanol and 1\% aqueous solution of glacial acetic acid as mobile phase. Elution was performed with composition gradient, meloxicam being detected at $355 \mathrm{~nm}$ with a 5 minutes analysis time. The method was tested on human plasma and pharmaceutical dosage forms.

Results: The retention time of the meloxicam was 3,7 minutes. Regression analysis showed good linearity, with correlation coefficient $\mathrm{R}=$ 0,9997; linear regression equation: $\mathrm{y}=206,1 \mathrm{x}-77,5$ over the $20-2000 \mathrm{ng} / \mathrm{ml}$ concentration range. Limit of detection was determined to be $5 \mathrm{ng} / \mathrm{ml}$ and limit of quantification was set at $15 \mathrm{ng} / \mathrm{ml}$. The recovery of the analyte in human plasma was low: 30,50\%, however it was reproducible, with a coefficient of variation of $4,83 \%$. The analysis of the tablets resulted in a $85,82 \%$ of meloxicam compared to the declared concentration.

Conclusions: The method proposed is quick, simple and adequate for detecting the meloxicam in human plasma. Although the recovery rate was low, it was reproducible, which leads to the fact, that improving extraction procedure can optimize the method.
\end{abstract}

Keywords: meloxicam, HPLC-UV, assay, pharmaceutical dosage forms

Received: 11 April 2014 / Accepted: 19 August 2014

\section{Introduction}

Meloxicam is a non-steroidal antiinflammatory drug from the subgroup of enolic acid -oxicams. Chemically, it is a 4-hydroxy-2-methyl-N-(5-methyl-2-thiazolyl)-2H-1,2benzothiazine-3-carboxamide-1,1-dioxide. It is highly selective for COX-II, resulting in potentially fewer side effects than non-selectiv COX- inhibitors and increased gastric tolerability. In clinical practice it is used for symptomatic treatment of osteoarthritis, rheumatoid arthritis and ankylosing spondylitis. After oral administration, meloxicam has an absolute bioavailability of $89 \%$, reaches peak plasma concentrations after 5-6 hours and the half-life is 20 hours $[1,2,3]$.

Different analytical methods have been reported for the determination of meloxicam in human plasma and pharmaceutical dosage forms like spectrophotometric methods, e.g. meloxicam complexation with Folin-Ciocâlteu reagent leads to a blue coloured compound with maximum absorption at $740 \mathrm{~nm}[4,5]$. Also voltammetric, turbidimetric, electrophoretic, polarographic, electrochemical methods have been developed for determination of this antiinflammatory drug $[6,7,8]$.
The literature survey reveals that liquid- chromatography methods: HPLC and LC-MS are the most commonly used methods for the study of meloxicam, especially in biological fluids. The reported chromatographic conditions are characterized by isocratic elution, using solvents such as acetonitrile, methanol, formic acid, acetic acid, tetrahydrofuran, phosphate buffer; separation on $\mathrm{C} 8$ or $\mathrm{C} 18$ columns; UV detection at 355,360 or $364 \mathrm{~nm}$ wavelength. Preparation of plasma samples involves liquid-liquid extraction, solid-phase extraction, cloud point extraction or protein precipitation [1,2,3,9-15].

The aim of the present study is the development of a simple and rapid HPLC-UV method for determination of meloxicam in human plasma and pharmaceutical formulations.

\section{Materials and methods \\ Reagents and chemicals}

- Meloxicam working standard with a purity of $99.5 \%$ obtained from Gedeon Richter Romania Ltd, produced by Unichem Roha, India.

- Gradient grade acetonitrile and methanol were supplied by Merck.

$-20 \% \mathrm{HClO} 4$ obtained from the dilution of $70-72 \%$ $\mathrm{HClO} 4$ p.a. Merck 
- $1 \%$ aqueous glacial acetic acid obtained from the dilution of glacial acetic acid p.a. Merck

- purified water HPLC grade

\section{Chromatographic equipment}

Merck Hitachi HPLC system consisting of: L-7100 quaternary pump, L-7200 autosampler, L-7360 column thermostat, L-7455 DAD detector, L-7000 interface, L-7612 degasser.

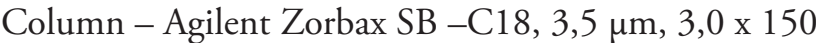
mm, batch: B08004.

\section{Preparation of stock solution and standard solutions}

$7,5 \mathrm{mg}$ meloxicam were weighed in a $25 \mathrm{ml}$ volumetric flask and dissolved in ultrasonic bath using acetonitrile as solvent to a solution with a concentration of $300 \mu \mathrm{g} / \mathrm{ml}$, diluted further more to $3 \mu \mathrm{g} / \mathrm{ml}$ - as stock solution in acetonitrile. By diluting the stock solution with water resulted calibration standards with the following concentrations: 20, 30, 100, 500, 700, 1000 and $2000 \mathrm{ng} / \mathrm{ml}$.

\section{Preparation of plasma samples}

Human plasma was obtained from the Medical Analysis Laboratory of Mureș County Clinical Hospital. $100 \mu \mathrm{l}$ standard solution of meloxicam $(2000 \mathrm{ng} / \mathrm{ml})$ was added to $900 \mu \mathrm{l}$ blank plasma samples. For protein precipitation, the plasma enriched with meloxicam was treated with 300 $\mu \mathrm{l} 20 \% \mathrm{HClO} 4$ solutions. The mixture was vortexed for $20 \mathrm{~s}$, then centrifuged for 10 minutes at $10000 \mathrm{rot} / \mathrm{min}$. The supernatant was transferred in chromatography vials. Five samples of this kind were prepared and then subject to chromatographic analysis.

\section{Analysis of meloxicam tablets}

20 tablets (15 mg meloxicam/ tablet) were powdered. A powder sample equivalent to $10 \mathrm{mg}$ meloxicam was weighed and transferred in a $25 \mathrm{ml}$ volumetric flask. Meloxicam was extracted into acetonitrile, using ultrasonic bath for 10 minutes. The solution obtained was filtered and diluted 1:1000 with water, obtaining a concentration of $400 \mathrm{ng} / \mathrm{ml}$.

\section{HPLC conditions}

The chromatography analysis was conducted on Agilent Zorbax SB - C18 column, 3,5 $\mu \mathrm{m}, 3,0 \times 150 \mathrm{~mm}$, at room temperature, the sample volume injected (Loop method) was $100 \mu \mathrm{l}$. The analysis time was set for 5 minutes. The elution was performed with composition gradient using methanol and 1\% aqueous solution of glacial acetic acid, whereas the flow rate was set for $1 \mathrm{ml} / \mathrm{min}$. The gradient elution programme is shown in table $\mathrm{I}$.

Spectra was recorded between $200-500 \mathrm{~nm}$, the chromatograms were extracted at $355 \mathrm{~nm}$ wavelength.

\section{Analysis of experimental data}

The experimental data was processed using the D 7000 HSM - System Manager Software and Microsoft Excel 2007 application.

Table I. Mobile phase composition

\begin{tabular}{ccc}
\hline Time (min) & Methanol & $\begin{array}{c}1 \% \text { aq. glacial } \\
\text { acetic acid }\end{array}$ \\
\hline 0 & $60 \%$ & $40 \%$ \\
\hline 3 & $70 \%$ & $30 \%$ \\
\hline 4 & $70 \%$ & $30 \%$ \\
\hline 4,1 & $60 \%$ & $40 \%$ \\
\hline 5 & $60 \%$ & $40 \%$ \\
\hline
\end{tabular}

\section{Results \\ Method development}

Chromatographic method development started with trying to find a suitable mobile phase, which leads to adequate peaks and short analysis time. Initially meloxicam was eluted with a mixture of water and acetonitrile gradient composition, resulting in broad peak with retention time of 7 minutes. Replacing water with $1 \%$ aq. glacial acetic acid, led to improved peak shape, but extended analysis time. Experimentation continued with replacing acetonitrile with methanol, which greatly improved peak shapes. A mobile phase consisting of methanol and 1\% aq. glacial acetic acid with gradient composition (methanol $60 \% \rightarrow 70 \%$ over 3 minutes) was found to be optimum, regarding analysis time $(5 \mathrm{~min})$ and peak shape: symmetric and narrow peaks. Based on the UV spectra, the optimal wavelength was set at $355 \mathrm{~nm}$ for analysis of meloxicam.

\section{Specificity}

The retention time of the meloxicam in these chromatographic conditions, was $3,7 \mathrm{~min}$. No interferences were detected at the retention time of the meloxicam on the chromatogram of a blank plasma sample (fig. 1, fig. 2) or on the chromatogram of a water sample.

\section{Linearity}

The calibration curve consisted in 7 points, concentrations ranged between $20-2000 \mathrm{ng} / \mathrm{ml}$ and were prepared and analyzed three times. In order to obtain the calibration curve, the average values of the peak areas versus concentration were plotted. The value of the correlation coefficient was $\mathrm{R}=0,9997$, values for slope and intercept were 206,1 and $-77,5$ respectively. Residuals ranged between $\pm 10 \%$ and no correlation with the theoretical concentration was observed.

\section{Limit of detection, limit of quantification}

These two parameters were analyzed on aqueous meloxicam solutions, diluted from the stock solution. The limit of detection was $5 \mathrm{ng} / \mathrm{ml}$, whereas the limit of quantification $15 \mathrm{ng} / \mathrm{ml}$. LOD and LOQ were considered using signal to noise ratios of 3 and respectively 10 . 


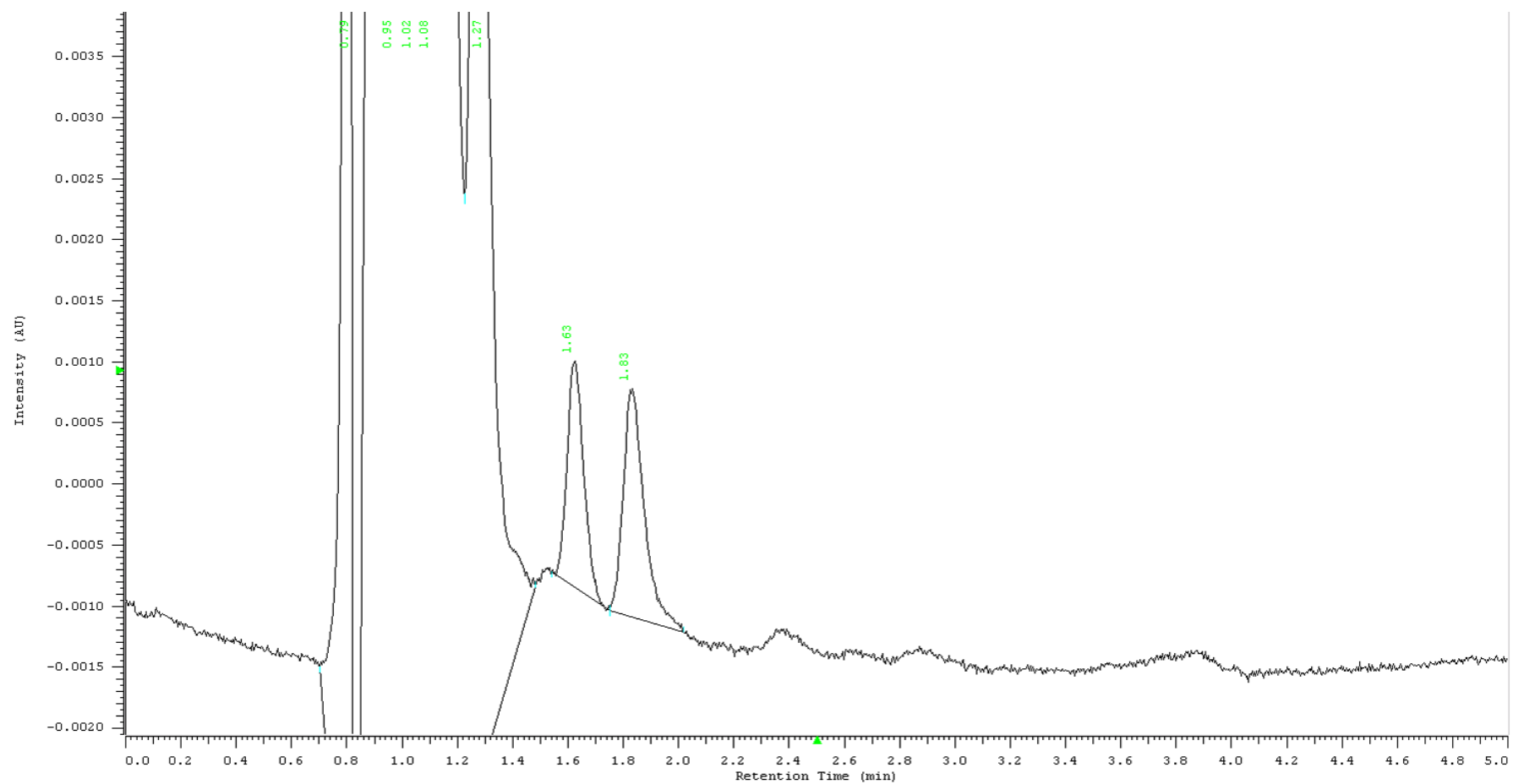

Fig. 1. Chromatogram of blank human plasma

\section{Method application for determinations in plasma}

Five plasma samples spiked with meloxicam were analyzed, the recovery of the analyte from plasma was $30,50 \%$. The coefficient of variation showed a value of $4,83 \%$.

\section{Method application for determinations in the pharma- ceutical product}

The chromatography method developed was tested on tablets containing meloxicam. The meloxicam content of the tablets was $85,82 \%$ compared to the concentration declared.

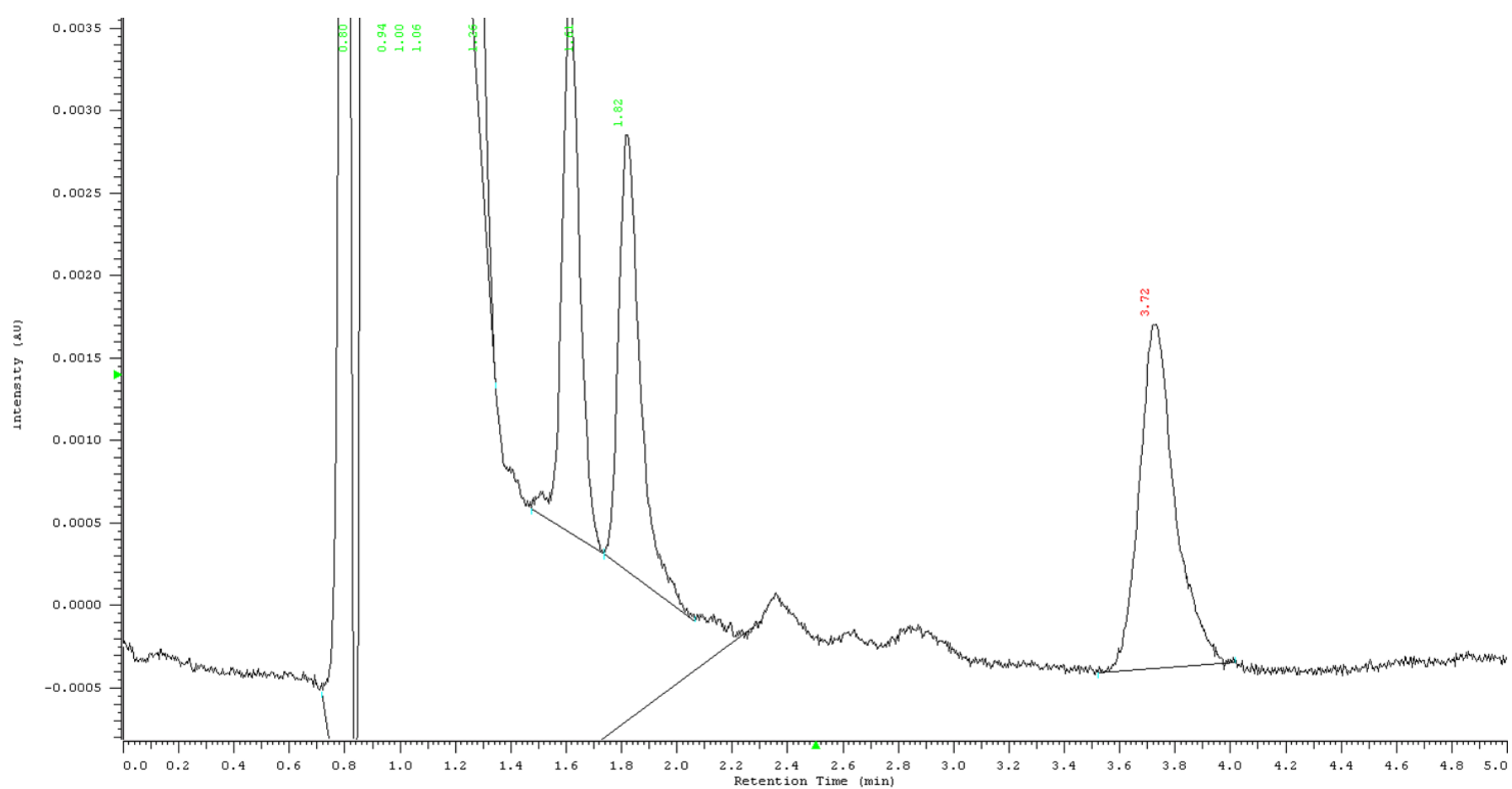

\section{Discussion}

HPLC-UV methods are used on large scale in pharmaceutical analysis and pharmacokinetic studies. The main purpose is the development of rapid, sensitive and economic methods.

In this study, a reverse phase HPLC-UV method was developed for measuring the meloxicam in human plasma and tablets. The decisive factors in choosing the chromatography conditions were the shape and symmetry of the meloxicam peak and the analysis time. Hence, the eluent made of methanol and $1 \%$ aqueous solution of glacial ace-

Fig. 2. Chromatogram of plasma spiked with meloxicam 
tic acid, with composition gradient, resulted in adequate peaks and short analysis time ( 5 minutes, in which column re-equilibration is included), whereas the retention time of the meloxicam was 3,7 minutes. Based on our results gradient elution reduced analysis time and improved peak shape compared with data from the literature, which reports isocratic elution and longer retention time $[1,13]$.

The analysis of meloxicam in human plasma showed a low recovery rate. One of the reasons could be the unoptimized extraction method through protein precipitation, since meloxicam is a substance which binds significantly to plasma proteins. The meloxicam content of the tablets $(85,82 \%)$ may have been influenced by the fact that they were close to the expiry date.

The low variability between the samples suggests that the improvement of the extraction method or performing a matrix matched calibration curve may lead to better results.

\section{Conclusions}

The HPLC method developed in this study is suitable to detect meloxicam in human plasma and pharmaceutical forms. The method proposed is simple, quick and economic. More thorough studies are required in order to validate the method, optimize the recovery rate, in view of using it in quantitative determinations, pharmacokinetic studies and routine determinations of pharmaceutical dosage forms.

\section{Acknowledgments}

This paper is partly supported by the Sectorial Operational Programme Human Resources Development (SOPHRD), financed from the European Social Fund and by the Romanian Government under the contract number POSDRU 80641.

\section{References}

1. Shaji J, Varkey D. Development and validation of a reverse phase-hplc method for determination of meloxicam in pharmaceutical dosage forms and human plasma. Int J Pharm Sci Rev Res. 2012;12:152-160.

2. Kimble B, Li KM, Govendir M. Quantitation of meloxicam in the plasma of koalas (Phascolarctos cinereus) by improved high performance liquid chromatography. J Vet Sci. 2013;14:7-14.

3. Bandarkar FS, Vavia PR. A Stability Indicating HPLC Method for the Determination of Meloxicam in Bulk and Commercial Formulations. Tropical Journal of Pharmaceutical Research. 2009;8:257-264.

4. Reddy MN, Murthy TK, Rajita K, Shankar DG. New Spectrophotometric Methods For The Determination Of Meloxicam. Indian J Pharm Sci. 2001;63:245-247.

5. Zawilla NH, Abdul-Azim Mohammad M, El Kousy NM, El-Moghazy Aly SM. Determination of meloxicam in bulk and pharmaceutical formulations. J Pharm Biomed Anal. 2003;32:1135-1144.

6. Murarasu AE, Mandrescu M, Spac AF, Dorneanu V. A method for the turbidity assay of meloxicam using molybdophosphoric acid. Farmacia. 2010;58:315-321

7. Altinoz S, Nemutlu E, Kir S. Polarographic behaviour of meloxicam and its determination in tablet preparations and spiked plasma. Farmaco. 2002;57:463-468.

8. Nemutlu E, Kir S. Method development and validation for the analysis of meloxicam in tablets by CZE. J Pharm Biomed Anal. 2003;31:393-396.

9. Zhang $\mathrm{H}$, Choi $\mathrm{H}$. Analysis of meloxicam by high-performance liquid chromatography with cloud-point extraction. Anal Bioanal Chem. 2008;392:947-953.

10. Rao RN, Meena S, Rao AR. An overview of the recent developments in analytical methodologies for determination of COX-2 inhibitors in bulk drugs, pharmaceuticals and biological matrices. J Pharm Biomed Anal. 2005;39:349-363.

11. Vignaduzzo SE, Castellano PM, Kaufman TS. Method development and validation for the simultaneous determination of meloxicam and pridinol mesylate using RP-HPLC and its application in drug formulations. J Pharm Biomed Anal. 2008;46:219-225.

12. Velpandian T, Jaiswal J, Bhardwaj RK, Gupta SK. Development and validation of a new high-performance liquid chromatographic estimation method of meloxicam in biological samples. J Chromatogr B Biomed Sci Appl. 2000;738:431-436.

13. Dasandi B, Shivaprakash, Saroj H, Bhat KM. LC determination and pharmacokinetics of meloxicam. J Pharm Biomed Anal. 2002;28:999 1004.

14. Rigato HM, Mendes GD, Borges NC, Moreno RA. Meloxicam determination in human plasma by high-performance liquid chromatography coupled with tandem mass spectrometry (LC-MS-MS) in Brazilian bioequivalence studies. Int J Clin Pharmacol Ther. 2006;44:489-498.

15. Sinha PK, Jeswani RM, Topagi KS, Damle MC. A validated RP-HPLC method for determination of Meloxicam in the Presence of its Impurities. International Journal of PharmTech Research. 2009;1:1051-1060. 